\title{
Some elementary musings on tragedy
}

\section{Mapping the area}

The best way to discuss tragedy is to fix the precise limits of its area. The first point to decide is: Are we to take tragedy as a certain kind of drama meant primarily for the stage, or to mean by it an expression of a particular approach to life, "the tragic sense", which is reflected both in novel and drama? Scholars are not unanimous in this regard. In the Middle Ages the word, tragedy was indeed applied to a narrative, not to a dramatic poem, that portrayed the fall of a man from a high station. (This is how Geoffrey Chaucer (c.1340-1400) defined tragedy in his Monk's Tale.) Raymond Williams, a more recent critic, has included works of fiction in his study. On the other hand, the definition of tragedy, given by Aristotle in his Poetics specifically excludes all narrative works (epic, for example) and insists on the invariable aspects that tragedy is the imitation which is "performed by actors, not through narration" (6.2). I quote from the recent translation by Malcolm Heath, which I believe, make better sense than what is found in earlier translations. For example, S. N. Butcher translated this passage as "in the form of action, not of narrative (1907, p.123) and Ingram Bywater as "in a dramatic, not in the narrative form" (1920, p.35). Malcolm Heath, however, is not alone in rendering the word dronton (literally, 'performed by men acting' the way he does. A. H. Gilbert too translated the passage as follows: 'presented by those who act' (1940, p.76). Before going further into this thorny issue, I want to make one point clear: I propose to follow Aristotle and other literary critics who would consider tragedy solely to mean a play, for this is how the term was first employed and generally understood. The term 'tragic' is now-a-days loosely applied to narratives only by way of extension.

The second issue that poses problems to students is: Does tragedy refer to the events that take place or to an individual? What tragedy? Or whose tragedy? The answer seems to be obvious, but is not. The question that automatically arises is: What constitutes the tragedy: the events themselves or the fate of the person who suffers the consequence? In other words, does tragedy lie in the suffering itself or in the sufferer? Here, too, critical opinion differs. There is a strong tendency to concentrate on the sufferer, that is, the central character in the play. In passing we may note that 'character' is a term free from gender bias. The central character may be masculine or feminine. There are tragedies named after males. Many Greek plays, such as Agamemnon by Aeschylus, King Oedipus by Sophocles and Hippolytus by Euripides, not to mention the four great tragedies of Shakespeare. But there are females among the titles too: witness The Suppliant Women by Aeschylus, The Women of Trachis by Sophocles, Andromacche, Hecuba and Medea by Euripides or Bérénice by Racine. So gender does not matter. Aristotle asserts that tragedy is "an imitation of an action". Speaking of the six component parts of tragedy, he assigns the first place to plot; character comes second. Since action is performed by certain agents, there needs must be people of a certain kind, who must appear in the story in a tragedy. He adduces no fewer than five reasons why plot is all-important (6.5-15).

In this respect, too, I propose to follow Aristotle. I would say that the tragedy lies in the events themselves; the central character is a mere agent. You may think that all this is just hair-splitting. Can there
Volume 3 Issue I - 2019

Ramkrishna Bhattacharya

Fellow, Pavlov Institute, Kolkata, India

Correspondence: Ramkrishna Bhattacharya, Fellow, Pavlov Institute, Kolkata, India,

Email ramkrishna.bhattacharya@gmail.com

Received: January 18, 2019 | Published: January 29, 2019

be any action without agents? There must be some person to perform the action. Are the story and the agents not inextricably connected? Or, to quote W. B. Yeats, can we separate the dancer form the dance? The answer is "Yes, they are". But here the question is of priority. Which of the two is the more important? The same agent may and do perform so many things, but all that he or she does would not generate tragedy. Therefore, action - a specific kind of it - is to be given more importance than the agent. For the present, I choose to refrain from enumerating other problems relating to this issue, for the fear that it may confuse you all the more. Let me further say at this point that no definite answer is to be expected to the more intricate questions that arise in relation to the Shakespearean tragedy, French neo-classical tragedy and modern tragedy. But it is necessary to start with certain assumptions and proceed on the basis of them. Such assumptions, called "postulates", may require considerable modifications when we come to face plays which do not conform to the existing theory or theories. Theorizing has to be reviewed or revised in the light of actual practice. So let us, at least for the time being, assume the limitations. I have mentioned: first, that tragedy in this discussion would refer to a particular kind of play, not to a lyric, or novel, or short story, and, second, that tragedy is caused by some event or events in a person's life, not primarily because of his or her being what he or she is.

Now to the phrase, "particular kind of play". What makes tragedy distinct from other kinds of play, such as comedy, farce, melodrama, pastoral, etc.? These too are plays with plot, character and other parts found in tragedy. Is it possible to mention any one characteristic as the determining mark of tragedy? The first characteristic that may readily come to your mind is unhappy ending. Alas! Actual practice belies such an all-so-evident notion. There are Greek tragedies - Euminides by Aeschylus, Philoctetes by Sophocles and a few other - the ending of which be called unhappy by any stretch of interpretation. Alcestis by Euripides has indeed a happy ending. And even though Oedipus in Sophocles' Oedipus at Colonus dies at the end, the play breathes a sense of relief: a long-suffering man, blind and wretched, is ultimately acquitted and purified from the sins he had committed unwittingly, all due to the caprice of the gods who decided to punish the son for the sin of his father. Aristotle, we should remember, never mentions "unhappy ending" or "death of the central character" or anything of that sort in his definition of tragedy. The only distinctive mark he ascribes to tragedy is, (pardon the Greek) spoudaias. This word has been the translator's despair. Some opted for the word "serious". This is how Bywater translated the passage: "A tragedy then is the imitation of an action that is serious and also as having magnitude 
complete in itself ..." (p.35). Margaret Habbard, on the other hand, rendered the passage as follows: "A tragedy is a mimesis [imitation, representation] of a high, complete action..." (p.57). More recently Malcolm Heath renders spoudaias as "admirable". I think Dorsch and Else are nearer the mark in the rendering of the phrase as "an action worth serious attention" (1965) and "an action which has serious implications" (1967) respectively. Hamilton Fyfe's "heroic" (1953) and Leon Golden's "noble" (1968) are too free adaptations to be admitted.

So the only distinguishing mark of tragedy is that it carries a graver import than any other kind of play "Having serious implications" is the key to the understanding of tragedy. All other features are incidental, not central to its being different from other kinds of plays. A tragedy is anything but a light-hearted play. The ending may be happy or unhappy. There may be multiple murders or no death at all. All these are of no consequence. You may at this point grumble and say: This fellow does not really tell us what tragedy is! He simply lays down his own conditions regarding the names and ends with a nebulous Greek word of baffling elasticity. I plead guilty. However, on the next occasion, I would try to elaborate, on the basis of concrete examples, what tragedy really is and which kinds of events lead to tragedy.

\section{Acknowledgment}

None.

\section{Conflicts of interest}

The author declares that there is no conflict of interest. 